\title{
Odor learning and odor discrimination of bees selected for enhanced hygienic behavior
}

\author{
Neloy Kumar Chakroborty ${ }^{1,3}$, Kaspar Bienefeld $^{2}$, Randolf MenZel ${ }^{1}$ \\ ${ }^{1}$ Institut für Biologie, Freie Universität Berlin, Königin Luisestr. 28/30, 14195, Berlin, Germany \\ ${ }^{2}$ Institute for Bee Research Hohen Neuendorf, Friedrich-Engels-Str. 32, 16540, Hohen Neuendorf, Germany \\ ${ }^{3}$ National Brain Research Centre Manesar, Gurgaon, NH-8, Haryana 122 051, India
}

Received 14 June 2014 - Revised 21 August 2014 - Accepted 5 December 2014

\begin{abstract}
Odor learning and odor discrimination were tested in a line of honeybees selected for increased hygienic behavior (HB) against the Varroa mite and compared with control bees (CB). Olfactory proboscis extension conditioning was used to quantify learning, discrimination, and generalization. Retention tests were performed after $1 \mathrm{~h}$ and after 1 day to probe the stability of memory. HB and CB did not differ in their learning, discriminating, generalizing, and remembering behavior when pairs of floral odors and pairs of sting pheromone and floral odor were tested. Colony odor used as a background odor during learning and discrimination reduced the performance in both groups, possibly due to an adaptation effect. This effect was found to be particularly strong in $\mathrm{CB}$. In both groups of test bees, no learning was found if wax caps of Varroa -infected and Varroa -uninfected cells were used as test stimuli, possibly because of the common odors. Volatile odors from Varroa-infected and noninfected pupae, however, were learned and discriminated indicating that the volatile signals are strong enough to override the similar cues of pupae. HB performed somewhat better than CB when infected pupae were used as the rewarded stimulus, but the difference between the two groups of test bees was small. Taken together, we conclude that odor learning and discrimination do not differ between $\mathrm{HB}$ and $\mathrm{CB}$ as long as general odors are involved, but when specific odor profiles from infected pupae are used as the reinforced signal, then a slightly better performance is seen in HB.
\end{abstract}

\section{Varroa destructor / hygienic behavior / PER conditioning / odor discrimination}

\section{INTRODUCTION}

Hygienic behavior is a behavioral defense mechanism used by honeybees to detect, uncap, and remove diseased, parasitized, dead, or otherwise abnormal brood from the colony (Rothenbuhler 1964). Honeybees also apply this defense mechanism to remove brood parasitized by the ectoparasitic mite Varroa destructor Anderson and Trueman (Boecking and Drescher 1991, 1992; Boecking and Spivak 1999; Peng et al. 1987; Spivak 1996). Therefore, hygienic behavior is one of the many heritable defense mechanisms that

Corresponding author: R. Menzel, menzel@neurobiologie.fu-berlin.de Manuscript editor: Bernd Grünewald honeybees use to combat brood diseases and Varroa mites (Harbo and Harris 2001; Spivak and Reuter 2001a). The term "hygienic behavior" has also been expanded to include the removal of brood killed by freezing or by pin-puncture (Spivak and Downey 1998) and brood invaded by the wax moth Galleria mellonella (Corrêa-Marques and David 1998; Villegas and Villa 2006) or by the small hive beetle Aethina tumida Ellis et al. (2003). Given the limited number of immune effector genes found in the honeybee genome (Evans et al. 2006), hygienic behavior is considered the most important social or group immune response which interferes with the life cycle of pathogens and removes them from the colony before they become virulent.

The Asian honeybee Apis cerana, the original host of $V$. destructor, is resistant to the parasitic 
mite (Peng et al. 1987). "Africanized honeybees" are hybrids of an African and a European subspecies of the western honeybee Apis mellifera and are assumed to have become tolerant to Varroa by restricting the size of the mite population (Martin and Medina 2004). However, most subspecies of A. mellifera exhibit weaker grooming and broodremoval behavior than $A$. cerana and have no effective resistance against Varroa (Peng et al. 1987; (Kralj et al. 2007; Kralj and Fuchs 2004; Yang and Cox-Foster 2007). Therefore, selective breeding programs aimed at developing A. mellifera lines that are resistant to the parasitic mite not only are crucial for achieving the longterm goals of the bee-keeping industry but also may provide a sustainable solution to the threat to bee health posed by toxic acaricides. In Europe, selective breeding programs have produced multiple $A$. mellifera lines with reported higher resistance (hygienic lines) against the Varroa mite compared to nonselected lines (nonhygienic lines) (Büchler et al. 2010). Different selection traits were used to produce these lines such as breeding for the trait of "Varroa surviving bees" or VSB (Fries and Bommarco 2007; Fries et al. 2006; Kefuss et al. 2009), selecting for slower mite population growth during the brood-rearing season, selecting drones under natural infestation pressure (Ehrhardt and Bienefeld unpublished data, Garrido and Büchler unpublished data cited in Büchler et al. 2010), or selecting for robust grooming behavior (Büchler 2000). Bienefeld et al. (2001) used the trait of selective uncapping of brood cells artificially infested with Varroa mites to produce specific hygienic honeybee line by artificially inseminating queens with sperm collected from drones raised from the selected uncappers (workers which showed outstanding performance in the task of uncapping).

Elucidating the behavioral and physiological mechanisms underlying hygienic behavior in individual honeybees is important to understand the nature of cues that may be involved in eliciting the brood removal behavior. Previous studies have demonstrated that bees utilize olfactory cues emanating from the parasitized pupae. Hygienic lines bred for the higher and faster removal of freezekilled brood were found to discriminate between the volatile odors of healthy and chalk broodinfested pupae significantly better than bees from nonhygienic colonies, although both types of bees learned to discriminate between floral odors equally well (Masterman et al. 2000). Hygienic bees also showed lower response thresholds and higher sensitivity to the chalk brood odors (pupae) compared to the nonhygienic bees (Masterman et al. 2001). Furthermore, bees from hygienic colonies collected during the time of uncapping showed significantly higher sensitivity and discriminability to the chalk brood odors than bees collected while performing the task of removal (Gramacho and Spivak 2003). A connection between olfactory cues and colony-level expression of hygienic behavior was also established by bioassays (Swanson et al. 2009). Healthy larvae were removed after they were treated with the chemical compound phenethyl acetate, a chemical found in the headspace volatiles of chalk brood-infected larvae but absent from the volatile profiles of healthy larvae. Studies on the Minnesota hygienic line $(\mathrm{MN})$ in the USA have shown that this line is not only resistant to chalk brood and American foulbrood but also associated with significantly lower mite loads than unselected colonies (Spivak 1998; Spivak and Reuter 2001a, b). Colonies bred for hygienic behavior against the chalk brood and foulbrood pathogens were also reported to show resistance against $V$. destructor (Ibrahim and Spivak 2006; Spivak 1998). These results suggest that honeybees may use common olfactory cues released from infected brood to elicit hygienic behavior. However, the rich collection of cuticular hydrocarbons of pupae and adult bees, which differ between healthy and Varroa -parasitized animals (Salvy et al. 2001), may also contribute to the odor signals of infested brood.

The contribution of odors emanating from the Varroa -parasitized brood in eliciting hygienic behavior has been investigated in several studies. Nazzi et al. 2004 found multiple unsaturated hydrocarbons such as Z-(6) and Z-(7) isomers of pentadecenes and heptadecenes expressed in quantitatively higher amounts in the headspace volatile profiles of the intact Varroa-infested brood cells (Nazzi et al. 2004). Healthy brood treated with pure Z-(6) pentadecene in a bioassay were removed significantly more than brood 
treated with the pure solvent. Previously, it was shown that honeybees parasitized by Varroa mites carrying the virulent strain of the deformed wing virus (DWV) sustained higher virus titers and showed more severe morphological deformities than bees infected with mites harboring low virus titers and possibly nonvirulent DWV strains (Bowen-Walker et al. 1999). In agreement with Bowen-Walker's study, Schöning and colleagues found that hygienic bees detected and preferentially removed the severely damaged broods, which had been artificially infested with virulent mites harboring the replicating DWV causing an overt or fatal form of infection in infested broods, than broods parasitized by less virulent mites which transmitted a covert form of DWV infection (Schöning et al. 2012). These authors reported the expression of compounds such as 2- and 3butanediol or 2- and 3-methylbutanoic acid in higher proportions in the volatile chemical profiles of broods carrying an overt DWV infection compared to the broods with covert DWV infection. They proposed that hygienic bees most probably detected the severely damaged pupae by these olfactory cues resulting in higher removal rates of these overtly infected broods.

However, there is still no direct evidence that hygienic bees are better than nonhygienics at detecting and discriminating between the odors of Varroa-parasitized and unparasitized brood. Here, we address this issue and test whether individual bees from a hygienic line differ in their learning, discrimination, and generalization between general odors (floral, pheromonal) and special odors from Varroa-infected materials. We used two kinds of honeybees (Apis mellifera carnica ) in this study: one from a bee line selected for improved uncapping of brood cells infested with Varroa mites (hygienic behavior, HB) (Boecking et al. 2000) and another kind from colonies not selected for hygienic behavior (control bees, CB). We applied the olfactory proboscis conditioning paradigm (Bitterman et al. 1983) to quantify acquisition, retention, and generalization of odor stimuli. In the first set of experiments, bees were tested in differential conditioning of floral odors. In the second set of experiments, a component of the sting pheromone, isoamyl acetate (IAA), was used for conditioning. This set of experiments also included tests in which HB and $\mathrm{CB}$ were adapted to the background odor of honeybee colony. The objective of these experiments was to test whether $\mathrm{HB}$ and $\mathrm{CB}$ differ in their performance when in-hive conditions were simulated. In the next set of experiments, we tested the two types of bees with the odor stimuli of wax caps collected from the Varroa -infected and noninfected brood cells. The objective was to test whether wax caps of both kinds have sufficiently different odor profiles which bees can discriminate and whether HB and CB differ in their abilities to learn the discrimination tasks. In a last set of experiments, we used whole pupae and asked whether $\mathrm{HB}$ are better than $\mathrm{CB}$ at detecting and discriminating between the volatile odor profiles of the infected and noninfected pupae. Our experiments indicate rather subtle differences of odor learning, retention, and generalization between $\mathrm{HB}$ and $\mathrm{CB}$, thus making it necessary to design the experimental procedures carefully and to interpret the data with great caution.

\section{MATERIALS AND METHODS}

\subsection{Honeybee lines}

A line of honeybees (Apis mellifera carnica) was selected for improved uncapping of brood cells artificially infested with Varroa mites at the Institute for Bee Research (Bienefeld et al. 2001). Bees from this line (called hygienic bees, $\mathrm{HB}$, of the $\mathrm{HB}$ breed) were used in our study. Control bees (CB) also came from the institute's line selected for honey production and gentleness. In several preexperiments, this line was found to be significantly less involved in hygienic behavior. Two colonies of each were used.

\subsection{Procedure for olfactory PER conditioning}

Honeybee foragers were used for the olfactory conditioning of the proboscis extension reflex. The four colonies used for these experiments were placed well apart in our bee garden in order to avoid any drifting of bees between colonies. One day prior to conditioning, bees were caught at the hive entrance when departing the hive and harnessed in small plastic tubes following the procedure described previously (Bitterman et al. 1983; Matsumoto et al. 2012). 
An equal number of $\mathrm{HB}$ and $\mathrm{CB}$ were used for each conditioning experiment. The number of bees tested in each experiment will be given in the legend of the respective figure. The total number of tested bees was as follows: HB 422 and CB 384. The bees were fed to satiation with $30 \%(w / v)$ sucrose solution and kept overnight inside a dark and humid Styrofoam box. Next morning, bees showing the extension of their proboscis in response to the sucrose stimulation of the antennae were used for proboscis extension reflex (PER) conditioning, which started 45 min later. Absolute and differential conditioning procedures were applied with different intertrial intervals (ITI) as described further below. In absolute conditioning, bees received four acquisition trials each consisting of forward pairing of the odor stimulus (conditioned stimulus, $\mathrm{CS}+$ ) with the sucrose reward (unconditioned stimulus, US). In differential conditioning, bees received six conditioning trials of CS+/US forward pairing and six presentations of an odor (CS-) that was not followed by sucrose reward leading to two forms of learning, excitatory, and inhibitory learning (Bitterman et al. 1983). CS+/US pairings and CS- presentations alternated leading to a total of 12 conditioning trials. Differential conditioning started with the CS+/US pairing. Retention tests consisted of CS+ and CS- presentations performed 1 and/or $2 \mathrm{~h}$ and 1 day after the conditioning procedure.

Odor stimuli were prepared by soaking a small piece of filter paper in $10 \mu \mathrm{L}$ of the respective odorant. The filter paper was placed in a $20-\mathrm{mL}$ plastic syringe. The odor stimulus lasted for $5 \mathrm{~s}$ during which the $20 \mathrm{~mL}$ airodor mixture was blown onto the antennae of the bee. Volatile odors accumulating in the headspace of the syringes were delivered through the odor delivery channels of a custom-built olfactometer controlled by the solenoid valves that were controlled by a computer program. The same olfactometer was used for all odor stimuli. The US (30\% sucrose solution) started $3 \mathrm{~s}$ after odor onset by first touching the antenna with a toothpick soaked with the sucrose solution, followed by feeding though the proboscis and lasted for $4 \mathrm{~s}$. The CS- trials lasted for $5 \mathrm{~s}$. A conditioned response (CR) consisted of the extension of the proboscis during the 3-s odor stimulation before the onset of the US. No US was presented during the retention tests.

\subsection{Odor stimuli}

Odors were either pure chemicals (1-hexanal, 1hexanol, geraniol, isoamyl acetate, Sigma-Aldrich,
Germany, 1-octanol, Roth, Germany) or biological odors (hive odor, wax caps, pupae). Both floral and pheromonelike odors were used in order to test whether $\mathrm{HB}$ and $\mathrm{CB}$ differ with respect to their learning, discrimination, and generalization to these two classes of odors. In some of the experiments, we tested also the response to an odorless syringe fitted just with the carrier of the odors, filter paper, in order to include a weak stimulus and test for discrimination and generalization to such a weak stimulus. Hive odor was prepared by cutting a hole in the rooftop of a hive containing a honeybee colony. The hole was covered with a nylon net to keep the bees inside the hive. An exhaust pipe (2.5-m length) fitted to the hole sucked the air from the colony and blew it onto the test bees. We added the sentence: The hive was located $2.5 \mathrm{~m}$ from the PER conditioning setup. Each test bee was first adapted for $4 \mathrm{~min}$ to the colony odor and then exposed to the conditioning trials. ITI in these experiments was $60 \mathrm{~min}$ in the constant presence of the colony odor. Retention tests were also performed under the same adaptation conditions $1 \mathrm{~h}$ after and 1 day after conditioning. Wax caps from brood cells that had been artificially infested with the foundress Varroa mites were collected 7 days after infection. Wax caps covering the healthy brood cells were collected from about equally aged brood cells. During the collection of wax caps, the reproduction status of the foundress mites (presence or absence of multiple offspring) was checked, and only caps were collected from brood cells containing reproducing mites. Fifteen freshly isolated wax caps (from infected or noninfected brood cells) were collected in the morning of the experiments, stored in glass syringes and kept at a temperature of $37^{\circ} \mathrm{C}$ during differential conditioning. Retention tests were performed $2 \mathrm{~h}$ after and 1 day after conditioning using the identical doses of freshly collected wax caps.

Odors from the Varroa-infected and noninfected pupae were tested in the following way: Recently capped fifth instar bee larvae were artificially infested with Varroa mites by opening the cells with a sharp razor blade and transferring foundress Varroa mites into the cells using a soft brush. Brood cells were then carefully resealed and cell positions were marked on top of a transparent sheet. Each larva was infected with three mother mites. Brood combs containing the infected and noninfected brood cells were kept inside an incubator $\left(37^{\circ} \mathrm{C}\right)$ for 7 days. Live pupae with light pink purple eyes were collected and used as the odor source for differential conditioning experiments. Ten infected and ten noninfected intact pupae were taken fresh from 
the brood cells, carefully placed without damaging their skins inside $12-\mathrm{mL}$ syringes and used as odor stimuli. Used batches of pupae were frequently replaced with fresh pupae. The same olfactometer as used for pure odorants was applied here. Bees were conditioned with an ITI of $14 \mathrm{~min}$, and retention tests were performed $1 \mathrm{~h}$ after and 1 day after conditioning using the same number of freshly collected pupae.

The odor used during the hive odor adaptation experiments was extracted from a colony whose bees were not genetically related to the $\mathrm{CB}$ and $\mathrm{HB}$ test bees.

\subsection{Statistical methods}

Honeybees that survived an entire experiment and showed the PER to sucrose at the end of the experiment were included in the data analysis. Repeated measures ANOVA (RM-ANOVA) test followed by the Fisher's LSD post hoc test were applied to compare the conditioned responses (CRs) of bees from the $\mathrm{HB}$ and $\mathrm{CB}$ colonies (Lunney 1970; Mota and Giurfa 2010; Rath et al. 2011). Mann-Whitney $U$ test was used to compare (within individual lines) the conditioned responses of bees from the $\mathrm{HB}$ and $\mathrm{CB}$ colonies to the alarm compound isoamyl acetate in the presence and absence of the background colony odor. Results of the associated RM-ANOVA tests will not be reported unless we found a significant interaction between the factors "stimulus" (stimulus type) and "time." Differences in conditioned responses were considered statistically significant when $P<0.05$. The programs used for these calculations were Statistica version 5.0 and MatLab from MathWorks.

\section{RESULTS}

\subsection{Experiment 1: differential conditioning with floral odors}

Here, we ask whether HB and CB differ in their abilities to learn and discriminate between floral odors. Both HB and CB learned to discriminate 1hexanal and 1-octanol (Figure 1). Successful learning was also seen in the retention tests. During the two retention tests, HB (first subplots in columns B and $C$ ) showed significantly higher responses to 1hexanal compared to 1-octanol. Similarly, CB (second subplots in columns B and C) also showed significantly higher CRs to 1-hexanal than 1octanol during the retention tests. When odor contingencies were reversed and 1-octanol was used as the $\mathrm{CS}+$ (Figure 1: third and fourth subplots in column A for $\mathrm{HB}$ and $\mathrm{CB}$, respectively), significant interactions between stimulus and trial were found for both $\mathrm{HB}$ and $\mathrm{CB}$. HB showed higher CRs to 1-octanol than 1-hexanal during the retention tests (third subplots in columns B and C); however, a significant difference was found only in the retention test performed after $2 \mathrm{~h}$. $\mathrm{CB}$, on the other hand, also showed significantly stronger CRs (fourth subplots in columns B and C) to 1-octanol in the 2-h test, but like HB, the difference in CRs was found just below the level of significance in the 1-day test. We conclude from these results that both HB and CB successfully learned and discriminated between these two floral odors. No difference in odor learning and odor discrimination was found between $\mathrm{HB}$ and $\mathrm{CB}$.

We repeated these differential conditioning experiments using the floral odors 1-hexanol and geraniol (Figure 2). Again, HB learned to differentiate between the $\mathrm{CS}+$ and $\mathrm{CS}-$ odors when 1-hexanol or geraniol was used as the $\mathrm{CS}+$. Unlike $\mathrm{HB}, \mathrm{CB}$ failed to learn the discrimination and showed generalization between the $\mathrm{CS}+$ and $\mathrm{CS}-$ odors during training (second subplot in column A). CB showed significantly higher $\mathrm{CRs}$ to the $\mathrm{CS}-$ than to the $\mathrm{CS}+$ during the first, second, and fourth conditioning trials when geraniol was used as the CS+. Significantly higher retention scores for both $\mathrm{CS}+$ odors during the first and the second retention tests were found in $\mathrm{HB}$ (Figure 2: first and third subplots in both columns B and $\mathrm{C}$ ). $\mathrm{CB}$, however, showed such differential retention scores only for the 1-h retention test when geraniol was the $\mathrm{CS}+$ and for the 1-day retention test when 1-hexanol was the CS+ (second and fourth subplots in columns B and C, respectively). Thus, acquisition appeared to be better in $\mathrm{HB}$ for this pair of floral odors, but the differences between CRs to the $\mathrm{CS}+$ and $\mathrm{CS}$ - odors became smaller between the retention tests.

\subsection{Experiment 2: absolute conditioning with a sting alarm pheromone compound, IAA}

In this experiment, we asked whether $\mathrm{HB}$ and $\mathrm{CB}$ differ in learning and discriminating a component of the sting alarm pheromone isoamyl 
A
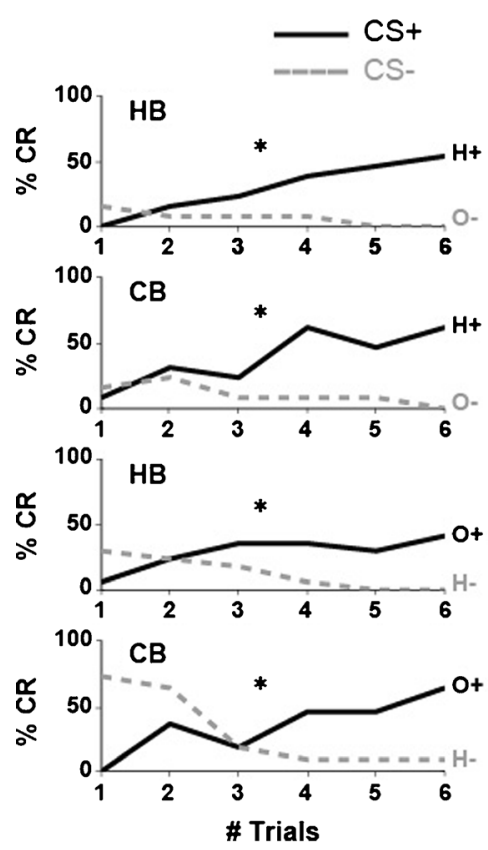

B
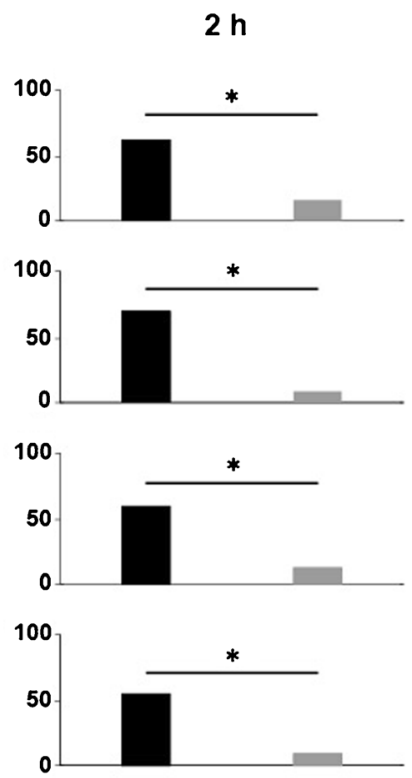

CS+
C
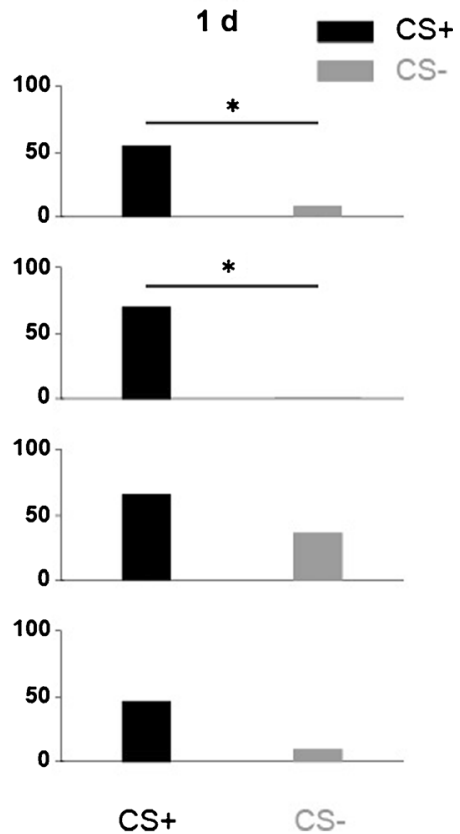

Figure 1. a Acquisition functions during differential conditioning of $\mathrm{HB}$ and $\mathrm{CB}$ with 1-hexanal and 1-octanol. 1Hexanal was used as the rewarded or $\mathrm{CS}+(\mathrm{H}+)$ and 1-octanol as the unrewarded or $\mathrm{CS}-\left(\mathrm{O}^{-}\right)$odors (upper two graphs ). 1-Octanol used as the rewarded $(\mathrm{O}+)$ and 1-hexanal as unrewarded $\left(\mathrm{H}^{-}\right)$odors (lower two graphs). The respective acquisition functions are marked with a solid line for the rewarded odor and with a dotted line for the unrewarded odors. Two-way repeated measures ANOVA (stimulus $\times$ trials) indicates significant differences (indicated with asterisks over line graphs) between the acquisition functions of both $\mathrm{HB}(N=13)$ and $\mathrm{CB}(N=13)(\mathrm{HB}$, $\left.F_{5,120}=6.951, P=0.00001 ; \mathrm{CB}, F_{5,120}=7.147, P<0.00005\right)$ for $\mathrm{H}+$ and $\mathrm{O}-($ first and second subplots in $\mathbf{a})$. When odor contingencies were reversed, significant differences were also found for both $\mathrm{HB}(N=17)$ and $\mathrm{CB}(N=11)$ (HB, $F_{5,160}=7.669, P<0.00005$; $\mathrm{CB} F_{5,100}=14.332, P<0.000001$ ). $N$ represents the number of bees used in an experiment. Retention scores at $2 \mathrm{~h} \mathrm{(b)}$ ) and 1 day (c) after training. The response probabilities to the CS+ and CSodors are represented by black and gray bars, respectively. Significantly higher response probabilities (denoted by asterisks ) to the CS+ compared to the CS- were found for the following test conditions: $\mathbf{b} \mathrm{HB}$ and $\mathrm{CB}$ trained with $\mathrm{H}+$ and $\mathrm{O}^{-}$and tested after $2 \mathrm{~h}$ (first, second subplots in $\mathbf{b}$; Fisher's LSD post hoc test: HB, $P=0.010$, CB, $P=$ 0.0002 ), $\mathrm{HB}$ and $\mathrm{CB}$ trained with $\mathrm{O}+$ and $\mathrm{H}^{-}$and tested after $2 \mathrm{~h}$ (third and fourth subplot in $\mathbf{b}: \mathrm{HB}, P=0.004, \mathrm{CB}$, $P=0.020$ ). $\mathbf{c} \mathrm{HB}$ and $\mathrm{CB}$ trained with $\mathrm{H}+$ and $\mathrm{O}-$ and tested after 1 day (first and second subplot in $\mathbf{c}: \mathrm{HB}, P=0$. 010, Co, $P=0.00004)$.

acetate (IAA) from a floral odor (1-hexanal) (Figure 3). Both HB and CB learned IAA. The two retention tests indicate that both $\mathrm{HB}$ and $\mathrm{CB}$ discriminated well between IAA and 1-hexanal (Figure 3b, c). We introduced two novel stimuli (1-hexanal, plastic syringe with filter paper) in the retention tests in order to uncover potential differences between $\mathrm{HB}$ and $\mathrm{CB}$ with respect to odor generalization. In such a case, this novel stimulus may elicit more different response levels to the novel stimuli. No significant difference was found. We conclude from these data that both $\mathrm{HB}$ and $\mathrm{CB}$ do not differ in the learning, retention, and generalization when a component of the sting pheromone is used as the CS+.

\subsection{Experiment 3: absolute conditioning with isoamyl acetate in the context of colony odor}

Odor discrimination within the hive may be affected by the strong background odor of the 

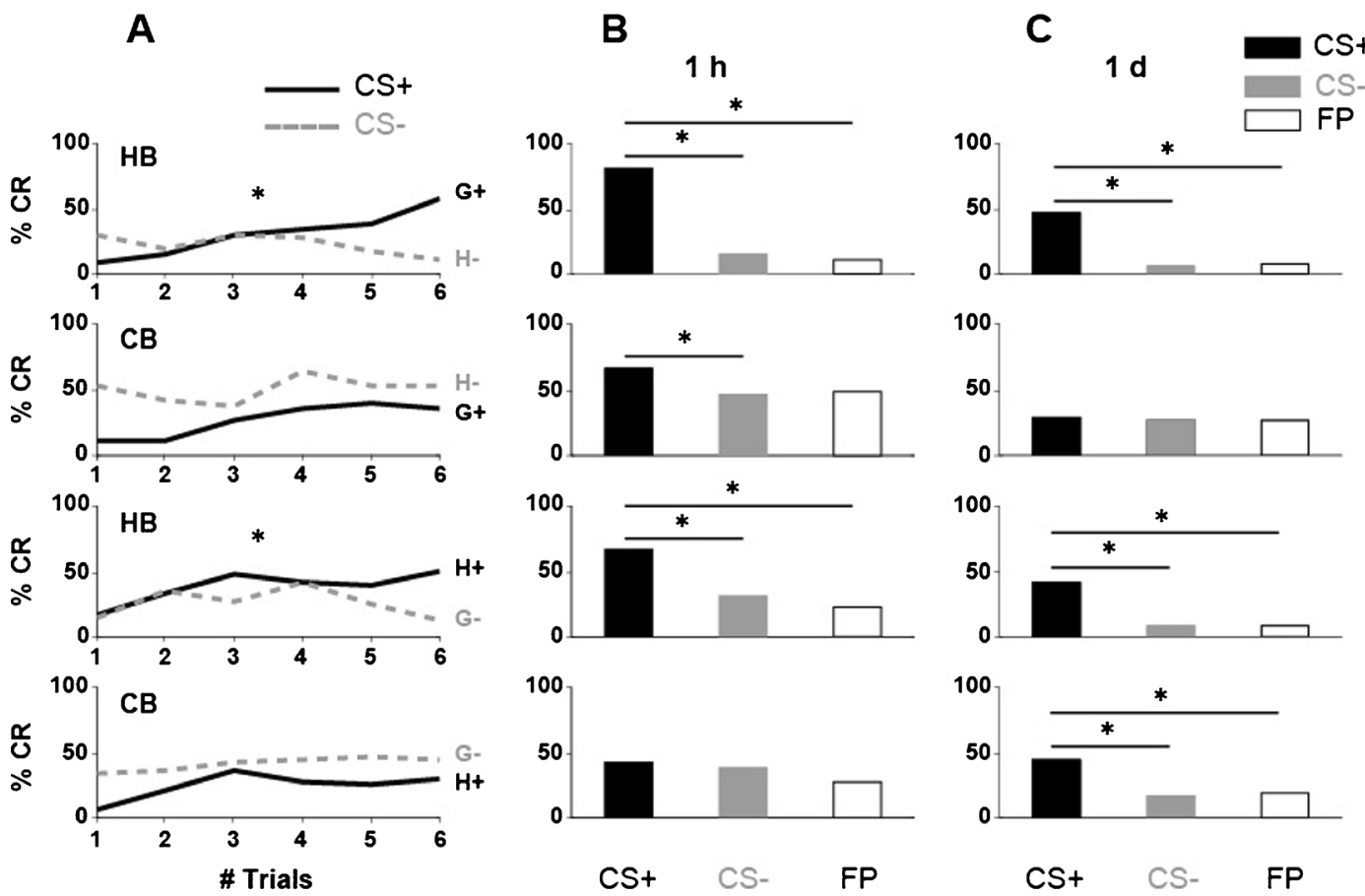

Figure 2. a Acquisition functions during differential conditioning of $\mathrm{HB}$ and $\mathrm{CB}$ with geraniol and 1-hexanol. Geraniol was used as the rewarded or $\mathrm{CS}+\left(\mathrm{G}^{+}\right)$and 1-hexanol as the unrewarded or $\mathrm{CS}^{-}\left(\mathrm{H}^{-}\right)$odors (upper two graphs ). 1-Hexanol used as the rewarded $(\mathrm{H}+)$ and geraniol as the unrewarded $\left(\mathrm{G}^{-}\right)$odors (lower two graphs). The respective acquisition functions are marked with a solid line for the rewarded odor and with a dotted line for the unrewarded odors. FP filter paper. Two-way repeated measures ANOVA (stimulus $\times$ trials) indicates a significant difference $\left(F_{5,460}=9.847, P<0.0005\right.$; denoted by an asterisk over the line graph) between the acquisition functions of $\mathrm{HB}(N=47)$ for the $\mathrm{G}+$ and $\mathrm{H}-$ (first subplot in a ). The acquisition functions of $\mathrm{CB}(N=45)$ (second subplot in a ) for the similar training condition are not significantly different $\left(F_{5,440}=2.171, P=0.056\right)$. When we reversed the odor contingencies (lower two graphs in a ), significant difference (denoted by an asterisk) was only found for $\mathrm{HB}$ $(N=48)$ and not for CB $(N=47)\left(\mathrm{HB}, F_{5,460}=3.613, P=0.003\right.$; $\left.\mathrm{CB}, F_{5,460}=0.728, P=0.602\right)$. Retention scores at the 1-h (b) and 1-day (c) tests after the training. The response probabilities to the respective CS+ odors are represented by black bars, CS- odors with gray bars, and filter paper with white bars. Significantly higher responses (denoted by asterisks ) to the CS+ compared to the CS- and filter paper were found for the following test conditions: $\mathbf{b} \mathrm{HB}$ and $\mathrm{CB}$ trained with $\mathrm{G}+$ and $\mathrm{H}^{-}$and tested after $1 \mathrm{~h}$ (first, second subplots in $\mathbf{b}$; Fisher's LSD post hoc test: $\left.\mathrm{HB}, P_{\mathrm{CS}+/ \mathrm{CS}_{-}}<0.0005, P_{\mathrm{CS}^{+} / \text {filter paper }}<0.0005, \mathrm{CB}, P_{\mathrm{CS}+/ \mathrm{CS}_{-}}=0.044\right)$ and $\mathrm{HB}$ trained with $\mathrm{H}+$ and $\mathrm{G}^{-}$and tested after $1 \mathrm{~h}$ (third subplot in $\mathbf{b}: P_{\mathrm{CS}+/ \mathrm{CS}_{-}}<0.0005, P_{\mathrm{CS}+/ \text { filter paper }}<0.0005$ ). $\mathbf{c}$ HB trained with $\mathrm{G}+$ and $\mathrm{H}^{-}$and tested after 1 day (first subplot in $\mathbf{c}: \mathrm{HB}, P_{\mathrm{CS}+/ \mathrm{CS}_{-}}<0.0005, P_{\mathrm{CS}+/ \text { filter paper }}<0.0005$ ), and $\mathrm{HB}$ and $\mathrm{CB}$ trained with $\mathrm{H}^{+}$and $\mathrm{G}^{-}$and tested after 1 day (third, fourth subplots in $\mathbf{c}: \mathrm{HB}, P_{\mathrm{CS}+/ \mathrm{CS}_{-}}<0.0005, P_{\mathrm{CS}+/ \text { filter paper }}<0.0005$, $\left.\mathrm{CB}, P_{\mathrm{CS}+/ \mathrm{CS}_{-}}=0.004, P_{\mathrm{CS}+/ \text { filter paper }}=0.008\right)$.

colony. We approached this question by exposing the bees to a discrimination task during exposure to the colony odor. Since colony odor is dominated by floral odors emanating from the pollen and nectar, we selected IAA as the CS+ and 1-hexanal as the CS-.

First, we asked whether colony odor compromised odor learning and discrimination and whether $\mathrm{HB}$ and $\mathrm{CB}$ deal with the colony odor differently (Figure 4). Indeed, acquisition functions are lower for learning in the context of colony odor in both HB and CB. Thus, odor detection and possibly discrimination may be more difficult within the colony.

Next, we asked whether differential learning and retention differ between $\mathrm{HB}$ and $\mathrm{CB}$ in the 

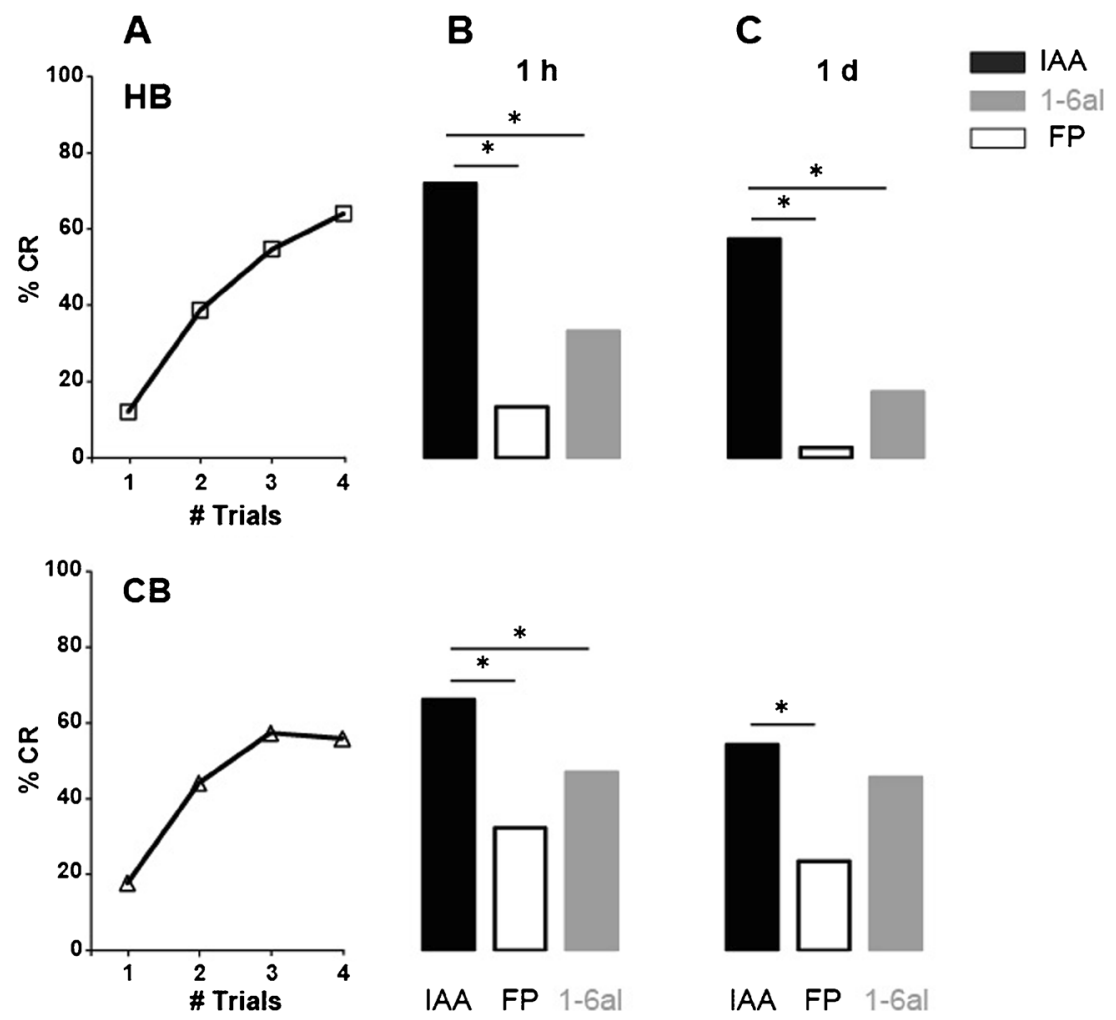

Figure 3. a Acquisition functions during the absolute conditioning of $\mathrm{HB}(N=75$ : upper line graph $)$ and $\mathrm{CB}(N=$ 68: lower line graph) to the sting alarm pheromone compound isoamyl acetate (IAA). Retention scores at the 1-h (b) and 1-day (c) tests after the conditioning. The response probabilities to the CS+ odor (IAA), untrained or CSodor (1-hexanal), and filter paper (FP, novel stimulus) are respectively represented with black, gray, and white bars . Significantly higher responses (denoted by asterisks) to IAA compared to 1-hexanal (1-6al) and filter paper (FP) were found for the following test conditions: HB (first subplots in b , c) 1-h (Fisher's LSD post hoc test: $P_{\text {IAA/1-6al }}<$ $\left.0.0001, P_{\mathrm{IAA} / \mathrm{FP}}<0.0001\right)$ and 1-day $\left(P_{\mathrm{IAA} / 1-6 a l}<0.0001, P_{\mathrm{IAA} / \mathrm{FP}}<0.0001\right)$ tests, CB (second subplots in $\left.\mathbf{b}, \mathbf{c}\right) 1-\mathrm{h}$ $\left(P_{\mathrm{IAA} / 1-6 \mathrm{al}}=0.020, P_{\mathrm{IAA} / \mathrm{FP}}=0.0007\right)$ and 1 -day $\left(P_{\mathrm{IAA} / \mathrm{FP}}=0.003\right)$ tests.

context of colony odor. Bees were conditioned with the CS+ IAA and tested with the CS- 1hexanal along with IAA. We also tested a novel odor (syringe plus filter paper) during the retention tests (Figure 5). Both HB and CB learned the $\mathrm{CS}+$ equally well in the presence of the colony odor (Figure 5: first and second subplots in column A). However, the retention tests indicated improved performances in HB since significant discrimination was found between the $\mathrm{CS}+$ and CS- and between CS+ and the novel stimulus (syringe plus filter paper) in HB. CB in contrast showed a lack of discrimination between the $\mathrm{CS}+$ and CS- during both retention tests (second subplots in columns B and C). We conclude that both $\mathrm{HB}$ and $\mathrm{CB}$ learned IAA in the background of colony odor and that retention is better in HB, both with respect to the discrimination of the $\mathrm{CS}+$ from the $\mathrm{CS}-$ and from a novel odor.

\subsection{Experiment 4: differential conditioning with wax caps isolated from Varroa - infected and noninfected brood cells}

Wax caps sealing the Varroa-infected brood cells may release odorants formed during the process of parasitization. We tested whether $\mathrm{HB}$ are better than $\mathrm{CB}$ in discriminating between the odors released from the wax caps collected from brood cells with Varroa -infected and noninfected pupae inside. Bees were conditioned in differential procedure, and retention was tested $2 \mathrm{~h}$ after 
A

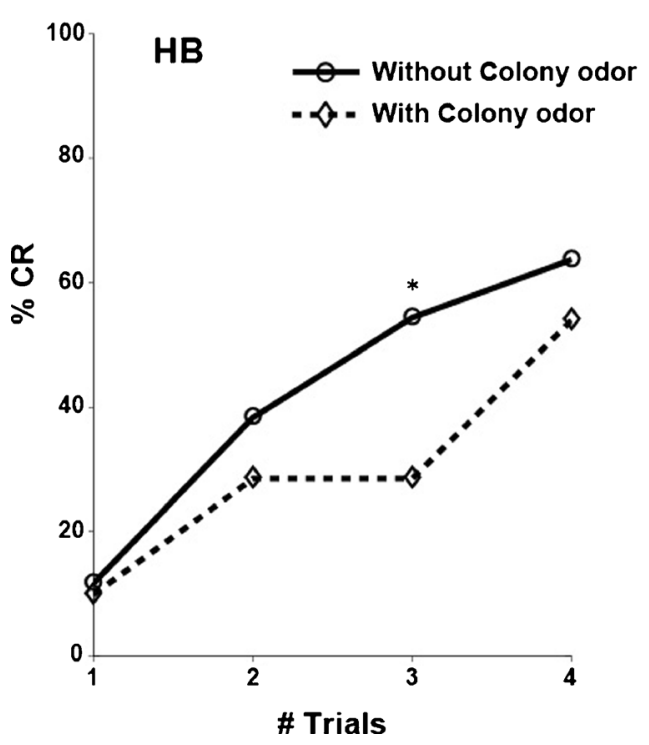

B

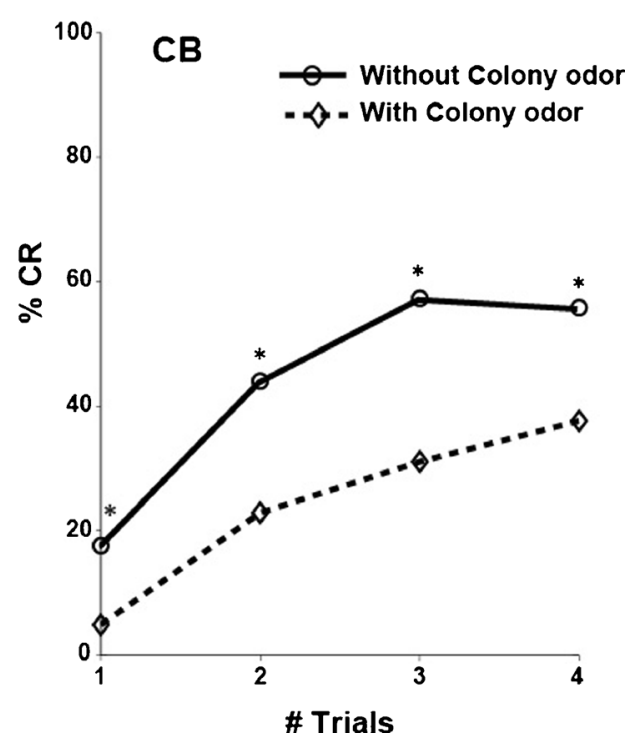

Figure 4. Acquisition functions of HB (a) and CB (b) to IAA in the absence (solid lines with open circles) and presence (dotted lines with open squares ) of the background colony odor. Mann-Whitney $U$ test found significant reduction in acquisition scores in HB during the third conditioning trial in presence $(N=59)$ of the background colony odor compared to the condition with no background $(N=75)$ odor $(U=1640.500, Z=2.987, P=0.002)$. CB showed significant reductions in CRs in all four conditioning trials in the presence $(N=61)$ of the background colony odor compared to no background $(N=68)$ (trial 1: $U=1810.00, Z=2.242, P=0.024$; trial 2: $U=1635.00, Z=2.521$, $P=0.011$; trial 3: $U=1530.500, Z=2.975, P=0.002$; trial 4: $U=1697.00, Z=2.056, P=0.039$ ).

and 1 day after conditioning (Figure 6). Both HB and $\mathrm{CB}$ failed to discriminate these wax caps in retention tests (Figure 6: first and second subplots in column A) although both $\mathrm{HB}$ and $\mathrm{CB}$ showed stronger responses to the CS- (infected caps) than the $\mathrm{CS}+$ stimuli throughout conditioning. $\mathrm{HB}$ (first subplots in columns B and C) and CB (second subplots in columns B and C) also showed no differences in the retention tests. When stimulus contingencies were reversed and infected, caps were used as the $\mathrm{CS}+$, both $\mathrm{HB}$ and $\mathrm{CB}$ again failed to discriminate between the wax caps in retention tests (Figure 6: third and fourth subplots in column A). Significant stimulus $\times$ trial interactions for the $\mathrm{HB}\left(F_{5,300}=2.680, P=0.021\right)$ and $\mathrm{CB}\left(F_{5,260}=6.526, P<0.0005\right)$ were found due to the higher number of responses to the $\mathrm{CS}-$ than to the $\mathrm{CS}+$ during conditioning. $\mathrm{HB}$ and $\mathrm{CB}$ also showed complete generalization in responses to the CS stimuli during the retention tests. The possibility of aversive volatile components emanating from the wax caps of infected brood can be excluded on the basis of these experiments which showed an equally strong generalization effect between the two kinds of wax caps.

\subsection{Experiment 5: differential conditioning with Varroa-infected and noninfected pupae}

In this experiment, we asked whether HBs are better than $\mathrm{CB}$ at discriminating between the odors of the Varroa-parasitized and nonparasitized pupae. When Varroa-parasitized pupae were used as the CS+ stimulus, HB learned the difference between the stimuli (Figure 7: first subplot in column A). In retention tests, HB showed a significantly higher response to the $\mathrm{CS}+$ than to the CS- (first subplots in columns $\mathrm{B}$ and $\mathrm{C}$ ). In contrast, $\mathrm{CB}$ did not learn to discriminate parasitized from nonparasitized pupae (second subplot in column A). These bees showed no significant differences in CRs during both retention tests (second subplots in columns B and C). 

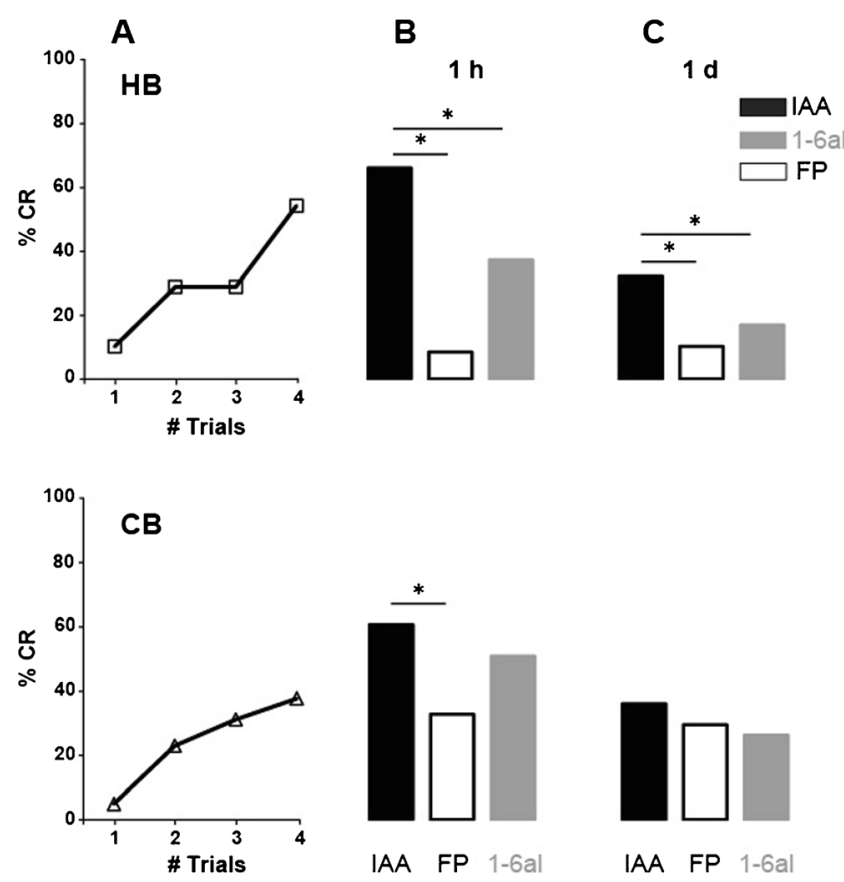

Figure 5. a Acquisition functions during the absolute conditioning of $\mathrm{HB}(N=59$ : upper line graph $)$ and $\mathrm{CB}(N=$ 61: lower line graph) to the alarm compound isoamyl acetate (IAA) in the presence of the background honeybee colony odor. Retention scores at the 1-h (b) and 1-day (c) tests after training. The response probabilities to the rewarded odor (IAA), untrained or CS- odor (1-hexanal), and filter paper (FP) are represented by black, gray, and white bars, respectively. Significantly higher responses (denoted by asterisks) to IAA compared 1-hexanal (1-6al) and filter paper (FP) were found for the following test conditions: HB: (first subplots in b , c) RM-ANOVA: significant stimulus $\times$ time effect $F_{2,174}=7.570, P=0.0007$; Fisher's LSD post hoc test 1 -h $\left(P_{\text {IAA1-6al }}=0.0001, P_{\text {IAA }}\right.$ $\left.\mathrm{FP}^{<}<0.00005\right)$ and 1-day $\left(P_{\mathrm{IAA} / 1-6 \mathrm{al}}=0.043, P_{\mathrm{IAA} / \mathrm{FP}}=0.0036\right)$ tests, CB: (second subplot in b $) 1$-h $\left(P_{\mathrm{IAA} / \mathrm{FP}}=0.001\right)$ test.

When nonparasitized pupae were used as the $\mathrm{CS}+$, HB failed to discriminate between the $\mathrm{CS}+$ and the $\mathrm{CS}-$ (third subplot in column A). However, significantly higher conditioned responses to the $\mathrm{CS}+$ than the $\mathrm{CS}-$ were found in the retention test after 1 day. $C B$, like HB, did not learn to discriminate between the two stimuli and showed higher responses to the $\mathrm{CS}^{-}$(infected pupae) than to the CS+ (uninfected pupae) (fourth subplot in column A). No significant difference in CRs was found during both retention tests (fourth subplots in columns B and C). We conclude from these results that HB performed slightly better in learning and discriminating between the volatile odors of the Varroa -infected and noninfected pupae but only when infected pupae were used as the rewarded stimulus.

\section{DISCUSSION}

In this study, we asked two questions: (1) Do $\mathrm{HB}$ and $\mathrm{CB}$ differ in their abilities to learn and discriminate between the floral and pheromonal odors, and (2) are HB better than CB at learning and discriminating between the odors associated with Varroa -parasitized and nonparasitized components of the honeybee colony?

HB discriminated between two pairs of floral odors (1-octanol vs 1-hexanal, and geraniol vs 1hexanol) and remembered the task for $24 \mathrm{~h}$, whereas CB learned to discriminate only the first pair of odors (1-octanol vs 1-hexanal) indicating a slightly better discrimination of general odors. However, the effect appears to be caused by a surprisingly low level of learning, retention, and discrimination of $\mathrm{CB}$ since acquisition and 
A

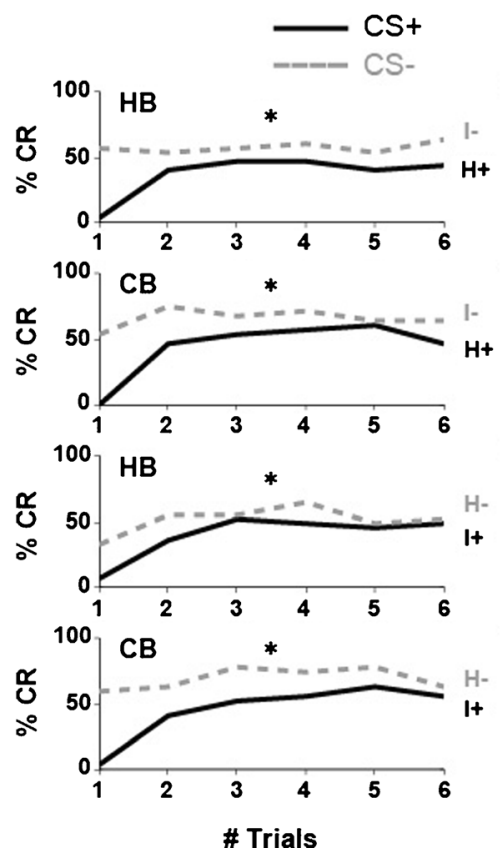

B

$2 \mathrm{~h}$
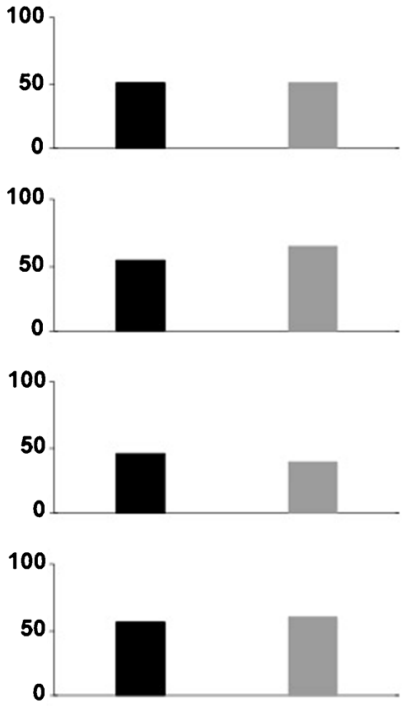

CS+
C

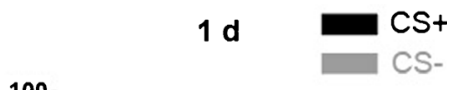

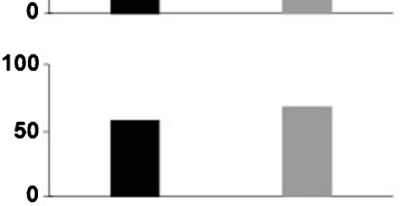
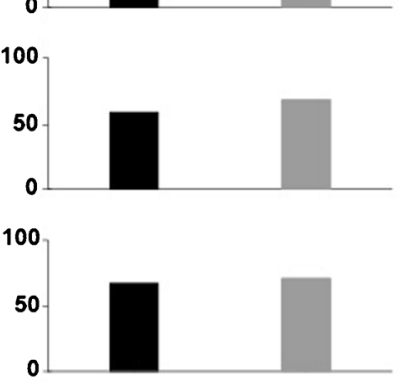

CS+

CS-

Figure 6. a Acquisition functions during the differential conditioning of $\mathrm{HB}$ and $\mathrm{CB}$ to the wax caps collected from Varroa -infected and from noninfected or healthy brood cells. Noninfected wax caps were used as the rewarded $(\mathrm{H}+)$ and infected caps as the unrewarded (I-) stimuli (upper two graphs). Infected wax caps were used as the rewarded $(\mathrm{I}+)$ and noninfected caps as the unrewarded $\left(\mathrm{H}^{-}\right)$CS stimuli (lower two graphs). Two-way repeated measures ANOVA test (stimulus $\times$ trial) indicates significant differences (indicated with asterisks over the line graphs) between the acquisition functions of both $\mathrm{HB}(N=30)$ and CB $(N=28)$ (HB: $F_{5,290}=9.365, P<0.0005$; CB: $\left.F_{5,270}=7.945, P<0.0005\right)$ for the $\mathrm{H}+$ and I- (first and second subplots in a ). In the reversed training condition (I+, $\mathrm{H}-$, lower two graphs in a ), significant differences were also found for $\mathrm{HB}(N=31)$ and $\mathrm{CB}(N=27)\left(\mathrm{HB}: F_{5,300}=\right.$ 2.680, $P=0.021$, Co: $\left.F_{5,260}=6.526, P<0.0005\right)$. Retention scores at the 1-h (b) and 1-day (c) tests after the training. The response probabilities to the respective CS+ odor are represented by black bars and those to the CSodor with gray bars . No significant difference between response probabilities to the CS+ and CS- stimuli was found for $\mathrm{HB}$ and $\mathrm{CB}$ during the retention tests.

discrimination scores for such floral odors are usually higher and do not differ from those found for HB (Ben-Shahar et al. 2000; Guerrieri et al. 2005; Malun et al. 2002). We do not know why our $\mathrm{CB}$ did not show the expected acquisition for both odor pairs equally well and did not remember the discrimination task equally well for both pairs during both retention tests (Figure 2). Masterman et al. (2000) also found that hygienic and nonhygienic bees discriminate equally well between geraniol and 1-hexanol. Also, no difference in odor discrimination was found between $\mathrm{HB}$ and $\mathrm{CB}$ in our test series when one odor was a component of the sting pheromone, isoamyl acetate (IAA). Sandoz et al. (2001) reported that bees generalize more strongly to floral odors during the retention test after being trained to IAA but less after training to floral odor. In our generalization test (no odor in the plastic syringe but only dry filter paper), a tendency was seen for $\mathrm{CB}$ to generalize more strongly, but the difference between $\mathrm{HB}$ and $\mathrm{CB}$ is not significant.

Odor discrimination in PER conditioning experiments is usually tested under conditions of no background odor, a test situation that does not capture the conditions inside the hive. It is not 
A
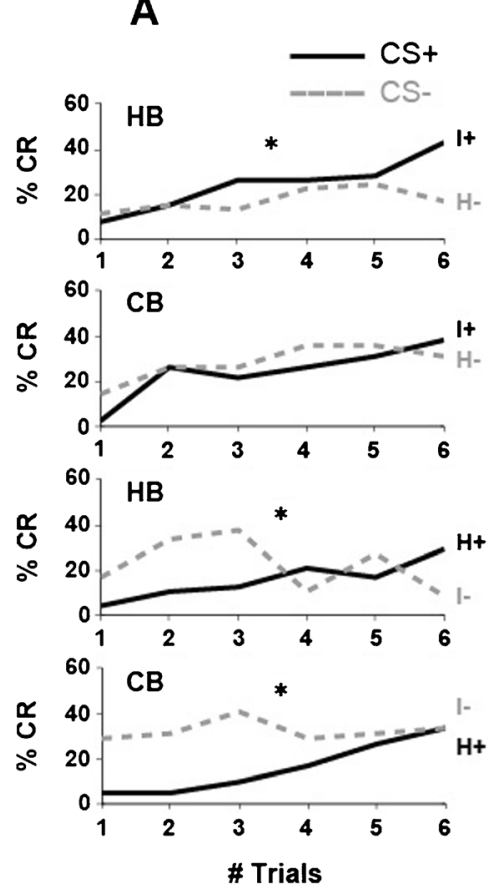

B
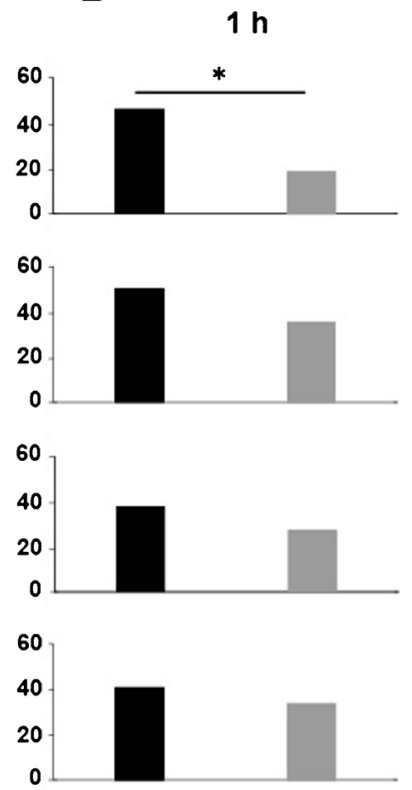

CS+
C
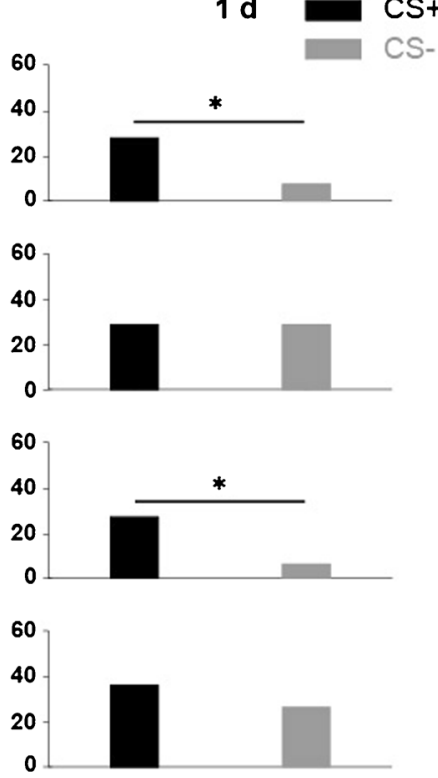

CS+
CS-

Figure 7. a Acquisition during differential conditioning of $\mathrm{HB}$ and $\mathrm{CB}$ to Varroa -infected and noninfected pupae. Varroa -infected pupae were the rewarded ( $\mathrm{I}+)$ and healthy pupae the unrewarded $\left(\mathrm{H}^{-}\right)$stimuli (upper two graphs ). Healthy pupae were the rewarded $(\mathrm{H}+)$ and Varroa -infected pupae the unrewarded stimuli (I-) (lower two graphs). The respective acquisition functions are marked with a solid line for the rewarded stimuli (I+ in the upper two graphs, $\mathrm{H}+$ in the lower two graphs $)$ and with a dotted line for the unrewarded stimuli $(\mathrm{H}-$ in the upper two graphs, $\mathrm{I}-$ in the lower two graphs). Two-way repeated measures ANOVA (stimulus $\times$ trials) indicates a significant difference $\left(F_{5,530}=2.678, P=0.021\right.$; denoted with an asterisk over the line graph) between the acquisition functions of $\mathrm{HB}(N=54)$ for the $\mathrm{I}+$ and $\mathrm{H}-$ (first subplot in a). The acquisition functions of $\mathrm{CB}(N=42)$ (second subplot in a) for the similar training condition are not significantly different $\left(F_{5,410}=0.753, P=0.58\right)$. In the reversed training condition, significant differences (denoted with asterisks) were found for both $\mathrm{HB}(N=48)$ and $\mathrm{Co}(N=42)(\mathrm{HB}$, $\left.F_{5,470}=7.251, P<0.0005 ; \mathrm{Co}, F_{5,410}=2.757, P=0.018\right)$ due to a higher number of responses to the $\mathrm{CS}-$ than to the $\mathrm{CS}+$ stimuli. Retention scores at the 1-h (b) and 1-day (c) tests. The response probabilities to the respective CS+ stimuli are represented with black bars and CS- stimuli with gray bars. Significantly higher responses were found for the following test conditions: $\mathrm{HB}$ trained to $\mathrm{I}+$ and $\mathrm{H}^{-}$and tested after $\mathbf{b} 1 \mathrm{~h}$ (first subplot in $\mathbf{b}, P=0.0005$ ) and $\mathbf{c}$ after 1 day (first subplot in $\mathbf{c}, P=0.011$ ). c $\mathrm{HB}$ trained to $\mathrm{H}+$ and $\mathrm{I}-$ and tested after 1 day (third subplot in c, $P=0.015$ ).

clear whether a background odor might reduce or enhance odor detection, learning, and discrimination since odor mixtures lead to nonlinear additive and subtractive effects (Galizia and Menzel 2000), possibly enhancing or reducing the neural codes of odors. We therefore exposed the test bees to a continuous stream of air that was sucked through a bee colony and selected IAA as the trained odor to make sure that the trained odor differs markedly from the background odor.
Furthermore, it is unlikely that these bees had learned IAA before in an appetitive context. Acquisition functions for IAA are somewhat lower possibly indicting an adaptation effect as seen, e.g., in the reduced behavioral responses of Drosophila flies to odors after been exposed to the same odor (Störtkuhl et al. 1999) and in the reduction in chemotaxis behavior to the preexposed odor stimuli in Caenorhabditis elegans (Colbert and Bargmann 1995). This apparently shows that 
colony odor interferes with the process of associative odor learning in honeybees. However, in the social environment of the hive, bees learn odors from each other, e.g., by trophallactic transfer of scented nectar (Arenas et al. 2008; Farina et al. 2005, 2007; Gil and De Marco 2005) and during dance communication (Grüter and Farina 2009). Hence, reduction in learning found in our study might be a specific effect of colony odor on the learning of sting pheromone odor IAA. IAA carries a very different biological meaning to the bees than floral odors. In the context of a colony while IAA is used to elicit alarm reactions or defensive behavior in bees, floral odors act as important cues controlling the choice of foraging on particular flowers. Therefore, the colony odor background possibly inhibited the learning of IAA as appetitive stimulus in this experiment.

When odor discrimination and generalization were tested with the colony odor background, $\mathrm{CB}$ showed higher generalization to the floral odor and to the air from the plastic syringe than $\mathrm{HB}$. CS+ and $\mathrm{CS}-$ discrimination is significantly better in $\mathrm{HB}$ than in $\mathrm{CB}$ during both retention tests supporting the view that $\mathrm{HB}$ performed better than $\mathrm{CB}$ in the presence of the colony odor background.

The most critical test in our attempt to search for differences between $\mathrm{HB}$ and $\mathrm{CB}$ in odor detection, learning, and discrimination should relate to chemical signals associated with Varroa infestation. Neither HB nor CB learned to discriminate between the wax caps from infected and noninfected cells. Most likely, highly salient odor signals such as decanal, octanal, furfural, and benzaldehyde (Blum et al. 1988), which were present in both kinds of wax caps, overshadowed the potential volatile chemicals released due to Varroa infection. Previous studies confirmed that the profiles of volatile chemicals differ between the Varroainfested and noninfested worker brood. These profiles vary with respect to some of the low molecular weight compounds (Nazzi et al. 2004; Schöning et al. 2012). Schöning et al. (2012) reported that brood parasitized by virulent Varroa mites (mites with a high chance of transmitting overt or fatal infections of deformed wing virus (DWV) in the infested brood) contain compounds like acetoin, 2and 3-methylbutanoic acid in higher proportions in their volatile chemical profiles compared to the volatile profiles of broods infected with the less virulent mites (mites with low potential to vector an overt infection of DWV in parasitized brood). The authors also found that bees in their hygienic behavior assays detected and then preferentially removed the severely damaged brood infested with the virulent mites. In our conditioning experiments, we used the infected wax caps from brood cells with reproducing mother mites which ensured successful parasitization. However, the levels of replicating virulent DWV in the parasitizing mites were not checked in our study. It is thus possible that we used foundress mites with low virulence levels to infest the larvae, which resulted in the formation of a different profile of volatile chemicals other than compounds such as acetoin, 2-methylbutanoic acid, or 2-, 3-butanediol.

We observed that both $\mathrm{HB}$ and $\mathrm{CB}$ responded more strongly to the CS- wax caps from parasitized brood cells than to the CS+ (wax caps from healthy brood cells) stimuli throughout the acquisition trials. This was possibly due to the conditioning protocol used here where bees were trained with the alternate $\mathrm{CS}+$ and $\mathrm{CS}-$ trials started with the $\mathrm{CS}+$ pairing with reward. Under conditions of complete generalization between the CS stimuli, response levels to the CS- were enhanced. We favor this explanation because similar effects were found in differential conditioning experiments with highly overlapping olfactory signals (Guerrieri et al. 2005).

Varroa-parasitized pupae as the CS+ were slightly better discriminated by HB than by $\mathrm{CB}$. In reversed training conditions with noninfected pupae as the CS+ and infected pupae as the CSboth $\mathrm{HB}$ and $\mathrm{CB}$ failed to learn the discrimination. The differences between HB and CB are small as one can see from the acquisition functions and by the fact that HB failed to show significantly higher retention score in the 1-h test when the healthy pupae were used as the $\mathrm{CS}+$. These results match previous reports on learning and discrimination of chalk brood-infected pupae by hygienic and nonhygienic bees (Masterman et al. 2000, 2001; Gramacho et al. 2003). Again, bees discriminated better when the chalk brood pupae were used as 
the CS+ and the healthy pupae as the CS-. Such an asymmetric discrimination may indicate more salient odor signals from the infected (Varroa or chalk brood) than the healthy pupae. Asymmetric odor discrimination has also been reported multiple times for PER-conditioned bees (Bitterman et al. 1983; Guerrieri et al. 2005; Bhagavan and Smith 1997).

We conclude that $\mathrm{HB}$ and $\mathrm{CB}$ do not differ when the task is to learn to discriminate pairs of floral odors and pairs of sting pheromone odor and floral odor. Colony odor as a background during learning and discrimination does not enhance performance but leads to a certain reduction in performance in both groups of test bees, possibly due to an adaptation effect. Under this test condition, HB showed better discrimination of the CS+ from both the CSodor and the novel stimulus during the two retention tests than CB. Since volatile odor cues from wax caps of Varroa -infected and noninfected cells were learned but not discriminated by both groups of test bees, it is likely that the common odors of wax caps overshadowed the performance. Volatile odors from the Varroa-infected and noninfected pupae, however, were learned and discriminated indicating that the volatile signals are strong enough to override the similar odor cues of pupae. An interesting asymmetry was found in the learning performance of the odor signals from the infected and uninfected pupae: if the infected pupae are the $\mathrm{CS}+$, then the discrimination was learned but not when the noninfected pupae were the $\mathrm{CS}+$. $\mathrm{HB}$ performed somewhat better than $\mathrm{CB}$ when infected pupae were used as the rewarded stimulus, but the difference between the two groups of test bees is small thus partially corroborating findings by Thakur et al. (1998) that learning had no effect on hygienic behavior against Varroa. Whether the small effect we see depends on better odor recognition or better learning cannot be resolved by our experiments. Taken together, our results show that odor learning and discrimination does not differ between $\mathrm{HB}$ and $\mathrm{CB}$ as long as the general odors are involved, except under the condition of colony odor background. Furthermore, when specific odor profiles from the Varroa-infected pupae are used as the reinforced signal, slightly enhanced performance was seen in HB.

\section{ACKNOWLEDGMENTS}

We thank Dr. Caspar Schöning for providing us with the bees from the different lines, for his continuous support during our experiments, for several in-depth discussions, and for his most helpful feedback on an earlier version of our manuscript. We also thank Dr. Dorothea Eisenhardt and Dr. Gerard Leboulle for stimulating discussions. Financial support came from the German Federal Ministry for Education and Research (BMBF) within the framework of the FUGATO program ( ref. no. 0315124A), from the European Union (according to regulation 1234/2007), and through grants from the Ministries of Agriculture of Brandenburg, Sachsen-Anhalt, Sachsen, and Thüringen, Germany, and the Senate of Berlin, Germany.

Apprentissage olfactif et discrimination olfactive d'abeilles sélectionnées pour leur comportement hygiénique bien développé

Varroa destructor / comportement hygiénique / conditionnement / PER / proboscis extension reflex

Duftlernen und Duftunterscheidung bei Bienen mit verstärktem Hygieneverhalten

Varroa destructor / Hygieneverhalten / Rüsselreflexkonditionierung / Duftunterscheidung

\section{REFERENCES}

Arenas, A., Fernández, V.M., Farina, W.M. (2008) Floral scents experienced within the colony affect long-term foraging preferences in honeybees. Apidologie 39 (6), 714-722

Ben-Shahar, Y., Thompson, C., Hartz, S., Smith, B., Robinson, G. (2000) Differences in performance on a reversal learning test and division of labor in honey bee colonies. Anim. Cogn. 3 (3), 119-125

Bhagavan, S., Smith, B.H. (1997) Olfactory conditioning in the honey bee, Apis mellifera : Effects of odor intensity. Physiol. Behav. 61 (1), 107-117

Bienefeld, K., Reinsch, N., Thakur, R. 2001. Selection for uncapping of Varroa infested brood cells in the honeybee (Apis mellifera ). In: Proc 37th Intern Apimondia Congress, Durban. Bucharest: Apimondia Publishing House. pp 12

Bitterman, M., Menzel, R., Fietz, A., Schäfer, S. (1983) Classical conditioning of proboscis extension in honeybees (Apis mellifera). J. Comp. Psychol. 97 (2), 107-119 
Blum, M.S., Jones, T.H., Rinderer, T.E., Sylvester, H.A. (1988) Oxygenated compounds in beeswax: Identification and possible significance. Comp. Biochem. Phys. B. 91 (3), 581-583

Boecking, O., Drescher, W. (1991) Response of Apis mellifera L colonies infested with Varroa jacobsoni Oud. Apidologie 22 (3), 237-241

Boecking, O., Drescher, W. (1992) The removal response of Apis mellifera L. colonies to brood in wax and plastic cells after artificial and natural infestation with Varroa jacobsoni Oud. and to freeze-killed brood. Exp. Appl. Acarol 16(4), 321-329

Boecking, O., Spivak, M. (1999) Behavioral defenses of honey bees against Varroa jacobsoni Oud. Apidologie 30 (2-3), 141-158

Boecking, O., Bienefeld, K., Drescher, W. (2000) Heritability of the Varroa-specific hygienic behaviour in honey bees (Hymenoptera: Apidae). J. Anim. Breed. Genet. 117 (6), 417-424

Bowen-Walker, P., Martin, S., Gunn, A. (1999) The Transmission of Deformed Wing Virus between Honeybees (Apis mellifera L.) by the Ectoparasitic Mite Varroa jacobsoni Oud. J. Invertebr. Pathol 73 (1), 101-106

Büchler, R. (2000) Design and success of a German breeding program for Varroa tolerance. Am. Bee. J. 140 (8), 662-665

Büchler, R., Berg, S., Le Conte, Y. (2010) Breeding for resistance to Varroa destructor in Europe. Apidologie 41 (3), 393-408

Colbert, H.A., Bargmann, C.I. (1995) Odorant-specific adaptation pathways generate olfactory plasticity in C. elegans. Neuron 14(4), 803-812

Corrêa-Marques, M.-H., David, D. (1998) Uncapping of worker bee brood, a component of the hygienic behavior of Africanized honey bees against the mite Varroa jacobsoni Oudemans. Apidologie 29(3), 283289

Ellis Jr., J., Richards, C., Hepburn, H., Elzen, P. (2003) Oviposition by small hive beetles elicits hygienic responses from Cape honeybees. Naturwissenschaften 90 (11), 532-535

Evans, J., Aronstein, K., Chen, Y., Hetru, C., Imler, J.L., Jiang, H., Kanost, M., Thompson, G., Zou, Z., Hultmark, D. (2006) Immune pathways and defence mechanisms in honey bees Apis mellifera. Insect Mol. Biol. 15(5), 645-656

Farina, W.M., Grüter, C., Díaz, P.C. (2005) Social learning of floral odours inside the honeybee hive. P. R. Soc. B. 272 (1575), 1923-1928

Farina, W.M., Grüter, C., Acosta, L., Mc Cabe, S. (2007) Honeybees learn floral odors while receiving nectar from foragers within the hive. Naturwissenschaften $94(1), 55-60$

Fries, I., Bommarco, R. (2007) Possible host-parasite adaptations in honey bees infested by Varroa destructor mites. Apidologie 38(6), 525-533

Fries, I., Imdorf, A., Rosenkranz, P. (2006) Survival of mite infested (Varroa destructor) honey bee (Apis mellifera) colonies in a Nordic climate. Apidologie $37(5), 564-570$

Galizia, C.G., Menzel, R. (2000) Odour perception in honeybees: coding information in glomerular patterns. Curr. Opin. Neurobiol. 10 (4), 504-510

Gil, M., De Marco, R.J. (2005) Olfactory learning by means of trophallaxis in Apis mellifera. J. Exp. Biol. 208(4), 671-680

Gramacho, K.P., Spivak, M. (2003) Differences in olfactory sensitivity and behavioral responses among honey bees bred for hygienic behavior. Behav. Ecol. Sociobiol. 54 (5), 472-479

Grüter, C., Farina, W.M. (2009) The honeybee waggle dance: can we follow the steps? Trends. Ecol. Evol. 24 (5), 242-247

Guerrieri, F., Schubert, M., Sandoz, J.-C., Giurfa, M. (2005) Perceptual and neural olfactory similarity in honeybees. PLoS biology 3 (4), e60

Harbo, J.R., Harris, J.W. (2001) Resistance to Varroa destructor (Mesostigmata: Varroidae) when miteresistant queen honey bees (Hymenoptera: Apidae) were free-mated with unselected drones. J. Econ. Entomol. 94 (6), 1319-1323

Ibrahim, A., Spivak, M. (2006) The relationship between hygienic behavior and suppression of mite reproduction as honey bee (Apis mellifera) mechanisms of resistance to Varroa destructor. Apidologie 37 (1), 31-40

Kefuss, J., Vanpoucke, J., Bolt, M., Kefuss, C. 2009. Practical Varroa resistance selection for beekeepers. Abstracts 41st Apimondia congress, pp. 15-20.09

Kralj, J., Fuchs, S., 2004. Parasite-host interactions between Varroa destructor Anderson and Trueman and Apis mellifera L.: influence of parasitism on flight behaviour and on the loss of infested foragers. Fachbereich Biologie und Informatik der Johann Wolfgang Goethe-Universität

Kralj, J., Brockmann, A., Fuchs, S., Tautz, J. (2007) The parasitic mite Varroa destructor affects non-associative learning in honey bee foragers, Apis mellifera L. J. Comp. Physiol. A. 193 (3), 363-370

Lunney, G.H. (1970) Using analysis of variance with a dichotomous dependent variable: an empirical study1. J. educ. Meas. 7, 263-269

Malun, D., Giurfa, M., Galizia, C.G., Plath, N., Brandt, R., Gerber, B., Eisermann, B. (2002) Hydroxyureainduced partial mushroom body ablation does not affect acquisition and retention of olfactory differential conditioning in honeybees. J. Neurobiol. 53 (3), 343-360

Martin, S.J., Medina, L.M. (2004) Africanized honeybees have unique tolerance to Varroa mites. Trends. Parasitology 20 (3), 112-114

Masterman, R., Smith, B., Spivak, M. (2000) Brood odor discrimination abilities in hygienic honey bees (Apis mellifera L.) using proboscis extension reflex conditioning. J. Insect. Behav 13(1), 87-101

Masterman, R., Ross, R., Mesce, K., Spivak, M. (2001) Olfactory and behavioral response thresholds to odors 
of diseased brood differ between hygienic and nonhygienic honey bees (Apis mellifera L.). J. Comp. Physiol. A 187 (6), 441-452

Matsumoto, Y., Menzel, R., Sandoz, J.C., Giurfa, M. (2012) Revisiting olfactory classical conditioning of the proboscis extension response in honey bees: a step toward standardized procedures. J. Neurosci. Meth. 211 (1), 159-167

Mota, T., Giurfa, M. (2010) Multiple reversal olfactory learning in honeybees. Front. Behav. Neurosci. 4, 1-9

Nazzi, F., Vedova, G., DAgaro, M. (2004) A semiochemical from brood cells infested by Varroa destructor triggers hygienic behaviour in Apis mellifera. Apidologie 35 (1), 65-70

Peng, Y.-S., Fang, Y., Xu, S., Ge, L. (1987) The resistance mechanism of the Asian honey bee, Apis cerana Fabr., to an ectoparasitic mite, Varroa jacobsoni Oudemans. J. Invertebr. Pathol 49(1), 54-60

Rath, L., Galizia, G.C., Szyszka, P. (2011) Multiple memory traces after associative learning in the honey bee antennal lobe. Eur. J. Neurosci. 34, 352-360

Rothenbuhler, W.C. (1964) Behavior genetics of nest cleaning in honey bees. IV. Responses of F 1 and backcross generations to disease-killed brood. Am. Zool 4 (2), 111-123

Salvy, M., Martin, C., Bagneres, A., Provost, E., Roux, M., Le Conte, Y., Clement, J. (2001) Modifications of the cuticular hydrocarbon profile of Apis mellifera worker bees in the presence of the ectoparasitic mite Varroa jacobsoni in brood cells. Parasitology 122 (02), 145-159

Sandoz, J., Pham-Delègue, M., Renou, M., Wadhams, L. (2001) Asymmetrical generalisation between pheromonal and floral odours in appetitive olfactory conditioning of the honey bee (Apis mellifera L.). J. Comp. Physiol. A 187 (7), 559-568

Schöning, C., Gisder, S., Geiselhardt, S., Kretschmann, I., Bienefeld, K., Hilker, M., Genersch, E. (2012) Evidence for damage-dependent hygienic behaviour towards Varroa destructor -parasitised brood in the western honey bee, Apis mellifera. J. exp. biol. 215(2), 264-271

Spivak, M. (1996) Honey bee hygienic behavior and defense against Varroa jacobsoni. Apidologie 27, 245260

Spivak, M., Downey, D.L. (1998) Field assays for hygienic behavior in honey bees (Hymenoptera: Apidae). J. Econ. Entomol. 91 (1), 64-70

Spivak, M., Reuter, S.R. (1998) Performance of hygienic honey bee colonies in a commercial apiary. Apidologie 29 (3), 291-302

Spivak, M., Reuter, G.S. (2001a) Resistance to American foulbrood disease by honey bee colonies Apis mellifera bred for hygienic behavior. Apidologie 32 (6), 555-565

Spivak, M., Reuter, G.S. (2001b) Varroa destructor infestation in untreated honey bee (Hymenoptera: Apidae) colonies selected for hygienic behavior. J. Econ. Entomol. 94 (2), 326-331

Störtkuhl, K.F., Hovemann, B.T., Carlson, J.R. (1999) Olfactory adaptation depends on the Trp Ca2+ channel in Drosophila . J. Neurosci. 19 (12), 4839-4846

Swanson, J.A.I., Torto, B., Kells, S.A., Mesce, K.A., Tumlinson, J.H., Spivak, M. (2009) Odorants that induce hygienic behavior in honeybees: identification of volatile compounds in chalkbrood-infected honeybee larvae. J. Chem. Ecol. 35(9), 1108-1116

Villegas, A., Villa, J.D. (2006) Uncapping of pupal cells by European bees in the United States as responses to Varroa destructor and Galleria mellonella. J. Apic. Res. 45(3), 203-206

Yang, X., Cox-Foster, D. (2007) Effects of parasitization by Varroa destructor on survivorship and physiological traits of Apis mellifera in correlation with viral incidence and microbial challenge. Parasitology 134 (03), 405-412 